\title{
A Branch and Bound based solution method for solving Vehicle Routing Problem with Fuzzy Stochastic Demands
}

\author{
Vishnu Pratap Singh ${ }^{1}$, Kirti Sharma ${ }^{1}$, and Debjani Chakraborty ${ }^{2}$ \\ ${ }^{1}$ Department of Mathematics, Visvesvaraya National Institute of Technology Nagpur \\ ${ }^{2}$ Department of Mathematics, Indian Institute of Technology Kharagpur
}

November 30, 2020

\section{Hosted file}

cvrpfsd.pdf available at https://authorea.com/users/373415/articles/495809-a-branch-andbound-based-solution-method-for-solving-vehicle-routing-problem-with-fuzzy-stochasticdemands 